\title{
MANAGING A SOUTH AFRICAN ORGANISATION WITHIN A DUAL MANUFACTURING AND SERVICES ECONOMY
}

\author{
Weeks, R \& Benade, S, Graduate School of Technology Management, University of Pretoria, South \\ Africa
}

\begin{abstract}
Purpose: The purpose of this paper is to analyse the nature of the South African dual manufacturing and services economy and the impact thereof on organisations from a management perspective.
\end{abstract}

Problem investigated: Services account for over $65 \%$ of South Africa's gross domestic product (GDP) and reflects an escalating trend. The manufacturing sector of the economy is just over $26 \%$ of GDP. This by implication implies that the South African economy is dualistic in nature. The economy functions as an integrated component of the global economy, one that is highly competitive and turbulent in nature. The traditional management approach tends to be one based on a mechanistic, analytical and deterministic manufacturing perspective that is no longer effective in dealing with the services economy.

Methodology: A literature study is undertaken and a narrative enquiry conducted by means of discussions with 24 South African executives to determine the impact of the dual economy on South African organisations and the influence thereof from a management perspective. The approach adopted was intentionally analytical-descriptive in nature. The narrative enquiry constituted open ended but structured discussions with executives in order to learn from their personal experiences in managing an organisation in what is termed to be the dual South African services and manufacturing economy.

Findings: An important conclusion drawn from the study is that traditional paradigms of management that evolved within a mechanistic manufacturing economy is no longer effective for dealing with the unpredictable and disruptive changes of a highly competitive global services economy. A complexity theory based management approach it would appear may be more relevant in dealing with the emergent realities associated with a turbulent services economy.

Value of the research: Seen within the context of the changing nature of the global and South African economy, the insights gained from the study could assist executives and managers in exploring alternative paradigms of management that would be more appropriate for dealing with the paradoxical nature of a dualistic economy.

Conclusion: Appropriate management paradigms differ in terms of contextual realities confronting managers, namely dealing with ordered and un-ordered contextual conditions. The Cynefin Framework (Kurtz \& Snowden, 2003) serves as a means of sense making in finding the most appropriate management response for dealing with the contextual realities associated with a dualistic economy.

Key words and phrases: A dualistic South African economy; complexity theory; Cynefin framework; global services economy, and innovation.

\section{INTRODUCTION}

"We pursue preservation. But the old order is doomed.

We value permanence. But permanence is the last refuge of those with shrivelled imaginations. We practice change. But change is not enough. (Not nearly.)"

Tom Peters, 2003:21.

The introductory quotation, by Tom Peters (2003:21), attests to the disruptive changes that confront the modern day business and industrial enterprise. Peters (2003:27) goes on to exhort executives and managers to "revel in the mess!". Without doubt this engenders a sense of discomfort in those who have become accustomed to and have gained there training and experience within a world of relative predictability associated with the manufacturing economic era. It is, however, an era that is rapidly making 
way for what has been termed to be the "services economy". Peters (2003:21) suggests that "we are, in fact, on the verge of the biggest and most profound wave of economic change in a thousand years". This posses the question as to how prepared South African executives and managers are for dealing with the challenges associated with managing an enterprise within an extremely competitive, disruptive and turbulent global services economy or as termed by Peters (2003:27) "the mess".

Traditional management paradigms associated with the manufacturing economic era are based on a more mechanistic, scientific, rationalistic, analytical, and deterministic perspective. It is a perspective that would seem to stand in contrast to the management paradigms of innovation, exploration, sudden disruptive change and uncertainty associated with an emergent services economy. What adds to this complexity is the fact that South Africa in fact reflects a dual economy of manufacturing and services, which in a sense entails a paradox in relation to management thinking. In this paper this management paradox is analysed with reference to the Cynefin sense-making framework (Kurtz \& Snowden, 2003 and Snowden \& Boone, 2007:72). It is suggested that the framework could serve as a means of sensemaking for dealing with the co-exiting realities of order and complexity associated with the South African dual economy.

In the ensuing section the nature of the South African dual economy is explored in relation to global economic trends. Having gained an insight into the nature of the economy the Cynefin framework is evaluated, in the subsequent section, as means of making sense of the management paradox that emanates from the impact of the dual economy on South African business institutions. The framework is then utilised as a source of reference in making sense of the emergent services economy. In the final instance a brief summary is presented of the conclusions drawn from the discussion and the implications for South African managers.

\title{
THE SOUTH AFRICAN DUAL MANUFACTURING AND SERVICES ECONOMY AND THE MANAGEMENT IMPLICATIONS ASSOCIATED THEREWITH
}

\author{
"Some 80 percent of GDP in the US and the EU originates in services. Together they account for \\ over 60 percent of world services exports."
}

Abimbola Akosile, 2008.

"With manufacturing slipping to less than 20\% of GDP and the role of services rising to more than $70 \%$ in some OECD countries, services are seen as playing a principle role in economies"

OECD, 2005.

From the introductory quotations it may be ascertained that the global economy has undergone a significant change in that services now account for over $60 \%$ of many countries economic activity. Fitzsimmonds and Fitzsimmonds (2008:3) confirm that the migration to the services economy is without doubt global in nature. South Africa is evidently no exception to the rule in this regard and as a result of sustained vigorous growth; services contributed in the region of 65 per cent to its GDP in 2005 (Lovelock \& Wirtz, 2007; OECD, 2005; OECD, 2007). The shift to services as a key driver of global economic growth has important employment implications in terms of skill in particular (Weeks, 2008:49). This needs to be seen in the context that South Africa's national market is deemed to be far too small to serve as a basis for sustainable economic growth and it is therefore deemed essential that it gains a significant share of the economic activity taking place in the global services marketplace. While, in terms of the World Economic Forum Global Competitive Index, South Africa has maintained its place among the top50 most competitive economies of the world, it has in effect slipped from the 42nd position that it held in 2005-2006, to $45^{\text {th }}$ place in 2006-2007. It is currently positioned at a slightly better 44th position for 20072008. Seen within the context of a highly competitive global marketplace this tendency is without doubt hardly conducive for significant future economic growth of the South African economy. It is suggested that the situation needs to be addressed with a sense of urgency if the economy is to continue to grow and meet the challenges associated with unrelenting trends of South African unemployment and poverty. It is therefore contended that South African enterprises need to adapt to the management challenges and realities associated with the transition to a global services economy. In this regard it is significant to note 
that within an American-centric context, Lohr (2006:1) argues that research and policy needs to reflect the realities associated with a services orientated economy, as more than $75 \%$ of American employees are currently employed within this sector of the economy.

With Services constituting more than $65 \%$ of the economy and manufacturing just over $30 \%$ it is contended that in practice South Africa has a dual economy. This presents executives and managers with a very specific management challenge, namely the integration of production and service related operational and value chain activities. At the core of the problem is the management "worldview" associated with each of these operational domains. The manufacturing worldview has its origins in a modernistic era of mechanistic scientific thinking and rational deductive decision-making. In contrast the services worldview is far more orientated towards a post-modern management orientation that embraces complexity. In this regard it is interesting to note that Eric Eisenberg (2006:1693) suggests that: "Many Westerners long for a simpler time where life-paths were clear. What we experience instead is a world of contradiction and confusion, where rampant subjectivity and diversity make plural that which was selfevident and certain, leaving us with a multiplicity of truths, reasons, and realities". At the very core of this dichotomy is the divergent management mindsets associated with manufacturing and services. From the statement by Eisenberg it may also be inferred that not only is the rate of change confronting South African institutions in the global services economy increasing, but the very nature of the changes that are occurring are changing as well. It would appear that they are turbulent in nature and largely preclude any ability of prediction in relation to the emergent outcome thereof. This gives rise to a multiplicity of truths and realities. This stands in contrast to a more traditional modernist sentiment of management, captured by Wildavsky (in Mertzberg, 1994:19), in claiming that "the virtue of planning is that it embodies universal norms of rational choice". Dalkir (2005:60) in a similar vein claims that traditional "decision making is situated in rational decision making models". It would therefore appear that sense and decision making models that evolved within a manufacturing context tend to conflict with the turbulent realities associated with a services economy. One of the executives interviewed in the course of this study in particular emphasised that pockets of stability are required within this turbulent context, if manufacturing operations are going to generate a sufficient return on their investment in plant infrastructure and ensure it viability.

In nature, services value chains differ from manufactured products quite fundamentally in many respects, so for instance services cannot be stored and in effect are intangible in nature. Services involve interaction with clients and are co-created and consumed simultaneously, a reality that clearly distinguishes it from manufacturing (Metters, King-Metters, Pullman \& Watson, 2006:6). Of particular relevance is the fact that service involves a fairly high degree of subjectively, being based on client perceptions and their expectations associated therewith. Generally service innovation is also associated with ideas and concepts that are difficult, if not near impossible, to patent. It may therefore be inferred that management paradigms associated with services and manufacturing of products have a very different orientation. Yet in a dual economy, where services and the manufacturing of products are increasingly becoming interwoven in the very fabric of the dual economy, the management realities associated therewith can no longer be ignored. This point was stressed by one of the managers interviewed in the course of this study. He in particular stressed that after sales services, in terms of their nature, are not very well dealt with by some manufacturing institutions. They apparently tended to approach the service related activities from a traditional mechanistic approach that did not take the emotional element of the service encounter into consideration.

In discussions with nine of the twenty four South African managers interview in the course of this study, it emerged that more often than not they are engaged in providing integrated and innovative solutions for clients that requires a fundamentally different management approach. Notable, these nine mangers came from organisations operating within diverse sectors of the South African economy, including that of engineering, manufacturing, and information technology. The approach is one of managing the complexity associated with the services economy, while simultaneously employing systems engineering concepts that have well established roots in a rich soil of traditional management theory and practice. One of the managers concerned indicated that his institution had recently been awarded a multimillion Rand contract for the supply of electronic equipment bases on the associated services that it could provide in relation thereto. The services related component of the contract and their perceived ability and 
capacity to deliver thereon, had in essence provided them with a competitive edge in a highly competitive marketplace. The services concerned constituted an ongoing research component, maintenance, training, and a transfer of operational and technical knowledge associated with the utilization of the equipment concerned. The narrative account of how the institution had acquired the tender reinforces the notion of the need for institutions to be able to provide an integrated business solution, to meet the diverse services and product related needs of clients.

Skills, knowledge and intellectual capital form a very definite profile, from a human perspective, in the services economy, which incidentally is often also referred to as the knowledge or information economy. The human aspects that are related with services are also clearly manifest in what is deemed to be the need to manage the client's "services experience" (Fritzsimmons \& Fritzsimmons, 2008:177). It incorporates feelings, values, beliefs, expectations, individual perceptions and emotions that traditionally would hardly form a very significant aspect of consideration in manufacturing operations. The accent in manufacturing tends to be on continuous improvement with respect to quality and in the reduction of costs associated with the manufacturing of the products concerned (Weeks, 2008:42). These human attributes, however, inherently need to be taken into consideration in marketing and providing clients with integrated business solutions. Within a global economy the integrated services and manufacturing value chains associated with many of these integrated business solutions extend beyond institutional, geographical and cultural boundaries. By implication, this increases the complexity associated with managing the operational activities associated therewith. A need to manage and nurture services ecology of relationships within a multi-cultural context therefore assumes relevance and adds to the complexity of managing the impact of a dual economy on an enterprise.

Within a manufacturing context control of operations forms an important traditional management tenet, yet within a services context people generally do not respond positively to a command and control management approach. Within a services ecology; teamwork, gaining consensus, negotiation, situational leadership, employee empowerment, and a host of similar participation management attributes and sensitivities assumes relevance. All of these attributes and sensitivities stand in stark contrast to a traditional manufacturing management paradigm of prescriptive rules, regulations, processes and procedures directed at ensuring operational efficiency and control. This very brief sketch of a few of the human aspects associated with having to manage integrated value chains in a dual economy, serves to provide some background as to the complex nature thereof from a management perspective.

From the preceding discussion it may be concluded that the dual economy generates a number of contrasting management paradoxes, paradigms and world views that co-exist in time, but differ in terms of economic context. In the subsequent section the Cynefin framework is evaluated as means of making sense of the management paradox that emanates from the impact of the dual economy on South African business institutions.

\section{THE CYNEFIN FRAMEWORK}

"The Cynefin framework helps leaders determine the prevailing operative context so that they can make appropriate choices."

\section{David Snowden and Mary Boone, 2007:72}

A central tenet that underpins the framework is the notion of order and un-order or as also referred to by Richardson (2008:14) complicated and complex systems. Ordered domains are deemed to be deterministic and predictable, in contrast to un-ordered domains where the focus is one of identifying patterns emerging from a fog of contextual uncertainty. Day and Shoemaker (2004:127) claim that managers today often conduct business in a fog of tremendous uncertainty, where the "world beyond their immediate vision remains elusive and emergent". They cite the Brent-Spar fiasco in the North Sea as a case in point where the Shell executives were unable to detect, identify and proactively react to the emerging trend of environmentalist protest associated with their intention to transform the obsolete drilling platform into an artificial reef. The ensuing consequence of this inability turned out to be an eventual full- 
scale boycott of the institution's gas stations in Germany. What the executives perceived as a minor event emerged as a trend that gained momentum with significant consequences, which at the time in question was not foreseen in the fog of uncertainty. It is this context of uncertainty and emergent trends that are difficult to detect that Snowden and Boone (2007:74) describe as being un-ordered and complex. Kurtz and Snowden (2002) suggest that this is the domain of complexity theory that is gaining increasing attention in economics and management. In a similar sense Axelrod and Cohen (1999:xi) similarly describe contexts challenging understanding and prediction, where small changes unleash major consequences, as complex adaptive systems.

People experience a sense of discomfort and unease when they are unable to determine and predict the outcome of future events with some degree of certainty. Predictability and being able to plan for the future provides a form of reassurance and stability that most people need in their lives, uncertainty in contrast engenders feelings of insecurity and in instances even fear. It is therefore not surprising that the accent traditionally has been on a need for making sense of the world we live in and being able to predict and plan for the future. Karl Weick and Kathleen Sutcliffe (2001:40) cite the challenger disaster as an example where engineers rationalised unexpected observations of potential O-ring failure by extending their definition of what constituted "acceptable risk" and so called normal erosion, thereby normalising the unexpected and avoiding having to make a possible false call that would have implications if found to have been incorrect. Perceptions of the unexpected are described as fleeting and if not acted on normalising activities ensue in order to deal with the associated increasing anxiety, tension and apprehension that stem from the uncertainty and unexpected. In the real world of the global economy it is suggested that these weak signals need to be taken into consideration as detected unexpected small and seemingly unimportant trends or events could well escalate into a tsunami of unanticipated proportions, the challenger disaster being a case in point.

The manufacturing era gave birth to a world view that may be encapsulated within what is frequently described as the scientific revolution. The mental impression or paradigms associated with the world view of science is generally one of research, experimentation, processes, systems, determinacy, accuracy, precision, and order. The contrast of order and un-ordered complexity is quite stark and it may be inferred that in practice they constitute two states of reality, one of which exists at a particular point in time. Stacey (2000:4), however, claims that organizations change in ways that display stability and instability, predictability and unpredictability. In effect the two states may therefore co-exist in time in different contexts. They in this sense are deemed to be intertwined. This by implication means that managers need to understand how and what constitutes effective management in each of these states.

Within a dual manufacturing and services economy operations management is complicated in that the value chains of the two have very fundamental differences, as previously alluded to. The dominant context of manufacturing tends towards the application of a systems engineering perspective of design, testing, production and eventual phase-out. Services operations, while in a sense incorporating similarities of systems engineering characteristics, simultaneously exhibit characteristics associated with complex adaptive systems theory. That implies that at a very fundamental level services need to be designed, implemented and managed, yet the very nature of the global services economy reflects a fog of competitive uncertainty and emergence that simultaneously needs to be dealt with in terms of the institution's operations. It is suggested that this intertwined contextual reality could be addressed, from a sense making perspective, by means of the Cynefin framework. The problem of information overload in dealing with services complexity is very real. Day and Schoemaker (2004:133) contend that the challenge is one of assembling the myriad pieces of information into a meaningful mosaic to create meaning out of apparent chaos.

The Cynefin framework has five domains, two of which exist in both order and un-order, with a fifth central area of disorder (Kurtz \& Snowden, 2002.). The domains in question are depicted in figure 1 (Kurtz \& Snowden, 2002:468). The two ordered domains are termed to be that of known and knowable order. The difference that exists relates to cause effect relationships that are readily able to be determined and alternatively only able to be determined by means of research and analysis. The two un-ordered domains are those of complexity and chaos. Snowden and Boone (2007:74) assert that in the un-ordered chaotic 
domain "a leader's immediate job is not to discover patterns but to stop the bleeding ... a leader must first act to establish order, then sense where stability is present and from where it is absent, then respond by working to transform the situation from chaos to complexity, where the identification of emergent patterns can both help prevent future crises and discern new opportunities".

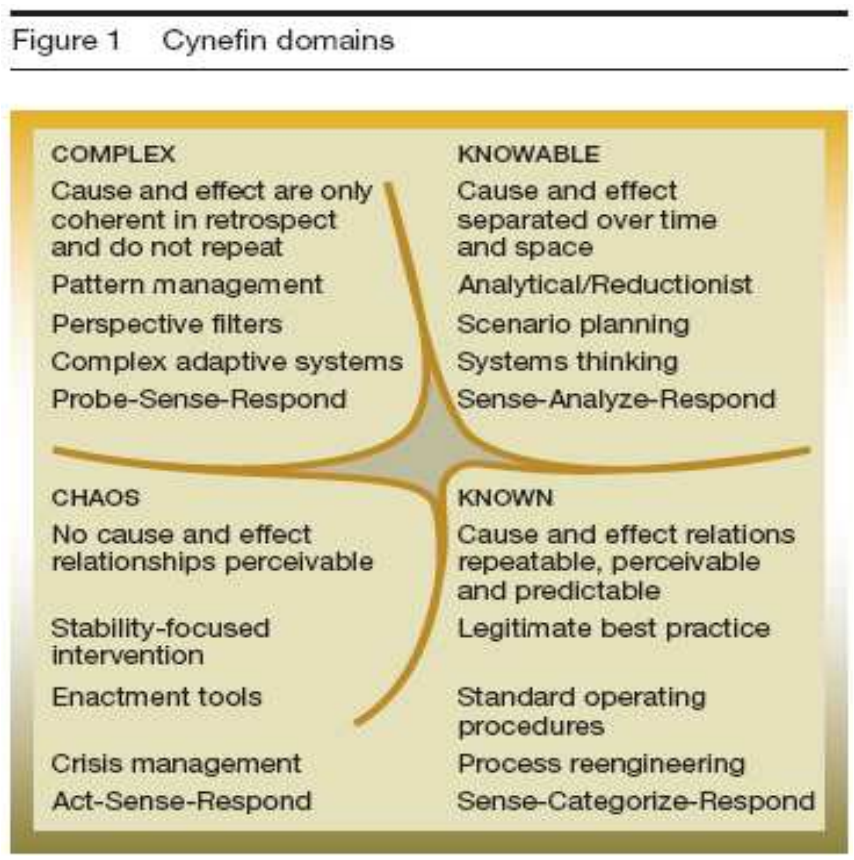

Source: Kurtz \& Snowden, 2002:468

Stacey (1992: 27-28) contends that traditional management thinking encourages executives to do nothing until being able to determine cause effect relationships. However, in contrast a more effect response appears to be one of soliciting employee creativity and innovation in attempting to create the future and learn there from. Brown (2008:86) similarly suggests that a shift from traditional manufacturing, to innovative and collaborative service orientated thinking is increasingly becoming evident. The contrasting responses tend to reflect a need for sense-making in order to apply the most effective response, in line with contextual realty of order and un-order. Within an ordered context a systems engineering approach, as previously discussed, has definite relevance. In contrast dealing with the emergent realities associated with the global services marketplace of complexity and chaos, requires a fundamentally different mindset. Notably, Snowden and Boone (2007:75) assert that "truly adept leaders will know not only how to identify the context they're working in at any given time but also how to change their behaviour and their decisions to match that context".

\section{THE CYNEFIN FRAMEWORK: A SERVICE SCIENCE PERSPECTIVE}

The process driven logic of a systems engineering approach is particularly effective in the known domain of order, where well established practices and process for dealing with manufacturing and services operations have been formalized and refined. Issues such as continuous improvement in quality and productivity are very typical management considerations within this context. Codes of practice and standards for manufacturing, the notion of best practices and similar considerations are central to this domain. The operational perspective focuses on the planning, implementation and management of the day-to-day activities of the institution. Supply chain management is one of the important aspects associated with the operational activities concerned, requiring a total systems view of the entire supply chain in relation to the institutions operational processes. Capacity planning plays an important role in this respect, as does supply chain modelling. The latter enables managers to determine the options that 
will best meet client needs at the most appropriate cost. At a strategic level the accent is on positioning the enterprise, taking its strengths and weaknesses into consideration, in order to capitalize on the opportunities presented within a highly competitive marketplace, while negating the potential threats that may exists in relation to its operational activities. Seen within the context of the global economy, it's competitive and highly turbulent nature and the move towards a services economy the strategic response may well not be one that can often be used as an appropriate response. A far more relevant strategic response may be one of approaching the services strategy from a complex domain perspective, where the accent is on managing emergent patterns.

The move to integrate services in the operational activities of the institution will entail the need to manage the services encounter and experience of clients. This introduces a human element of perception, feelings and emotions to the management issues that need to be dealt with. An important aspect of services activities therefore relates to what may be termed customer relations management. Aspects relating thereto such as the design and layout of services facilities are often referred to as "servicescapes" (Fitzsimmons \& Fitzsimmons, 2008:198). It is a concept that introduces aesthetics and an image and feeling congruent with services, from a management perspective. In this sense it is an inherent aspect that can be accommodated by adopting a systems engineering approach. The environmental considerations are important as the client takes part in what is termed to be a co-creation of the services experience (Fitzsimmons \& Fitzsimmons, 2008:18). A client-centric approach implies a need for support systems that enhances the customers' services experience and technology may well play a fundamental role in this regard. In many instances technology introduces standardized service processes, ATMs being a case in point. Standardisation may be considered to be an appropriate response within the orderedknown context. Self-service is a typical services encounter that may be controlled by the client, while the actual standardised service offering is defined by the bank in terms of their interpretation of client needs.

The human aspects associated with services delivery, such as client expectations and needs, may not always be readily apparent but could well still be determined by means of appropriate research, the outcomes of which can inform the services design process and servicescapes layout. This would imply that the ordered-knowable domain could assume relevance in this regard, from a sense making perspective. Team and networking to find creative and innovative solutions that will meet client expectations and services needs forms an important aspect in the knowable domain in that it tends to disrupt well entrenched and entrained moulds of traditional thinking. Snowden and Boone (2007:72) mention the opening up of brainstorming sessions for wider consultation across departmental and organizational boundaries in order to uncover and solicit new perspectives and ideas. Clients themselves may be drawn into these open ended brainstorming discussion sessions and thereby become part of the solution, as opposed to remaining part the problem in services delivery. An organization that has attempted to generate multiple perspectives, from diverse sources, in relation to finding new innovative solutions for issues confronting communities is IBM. It has launched what it terms to be the Global Innovation Outlook (GLO) initiative, which in 2006, brought together thought leaders from across the world on four continents, from diverse backgrounds, to take part in "deep dive" sessions to discuss challenges that affect business and society (IBM, 2006:3). In this domain the accent is not on find a so called best solution but on exploring alternative ideas, views, insights and experiences to generate innovative ways of addressing the relevant challenges concerned.

Within a very competitive dual economic marketplace business institutions need to focus on to gain a competitive edge in terms of innovative business models, products, services, use of technology, and similar means to gain a competitive advantage that is in line with their core business activities. The integration of services and manufacturing value chains offers a host of opportunities for innovation in order to gain a competitive advantage in terms of offering a complete integrated solution. Within the financial marketplace institutions attempt to offer clients a series of alternative solutions that may meet their requirements as no one solution may best serve all clients diverse needs. Increasingly the accent is in providing clients with customized services and products from a selection of alternatives that may be put together in a packaged solution. Innovation in generating these components and their integration can provide institutions with a competitive edge in the marketplace. Consultants provide clients with a very specific type of service, namely finding or generating innovative solutions that will meet clients' needs and 
they in particular typically operate within this domain. A similar case in point is within the health industry, where doctors provide patients with a diagnosis based on their specific symptoms and in some instances test results and prescribe a combination of medication and treatment that is best suited for addressing the specific nature of the problem in question. This stands in contrast to merely purchasing a standard off the shelf medication for a common cold. A few of the executives interviewed, in terms of this research study, indicated that increasingly services require some form of customisation in order to meet clients divergent needs and this by implication entails a move from traditional standardised offerings in order to gain a competitive advantage in the marketplace. It is suggested that this approach is more in line with a complexity perspective where the accent is on managing emergent patterns.

From the discussion it will have become clear that the Cynefin model can serve as a means for identifying, making-sense of and distinguishing between a known domain, where a specific best solution is available, and the knowable domain where a good integrated solution may be found. From an operations perspective this has very distinctive management, diagnostic and innovation skills implications. Brendan Peacock (2008:17) draws the conclusion that South Africa is stuck in a productionand manufacturing-focused mindset and has not yet entered the demand-driven phase of customization. Peacoack (2008:17) goes on to suggest that "business is won or lost on integration relationships and service". Tidd and Hull (2005:4), in researching management services innovation, contend that "the dominant management research and literature on new product and service development seeks to identify and promote the notion of 'best practice'". This would seem to suggest being trapped within a "knowndomain" management paradigm and a need for being able to more effectively respond to prevailing contextual conditions within the marketplace. This in turn would imply a need for an awareness and understanding of the appropriate response associated with each of the Cynefin framework domains, as well as an ability to move through the different management paradigms associated with each of the domains in question. It is suggested that this provides a new perspective on the often claimed need for flexibility in dealing with contextual turbulence and uncertainty.

Miles (2005:81) claims that the term "knowledge-base economy" has been introduced to characterize some of the main developments in industrial societies during the end of the late $20^{\text {th }}$ and early $21^{\text {st }}$ century. Miles $(2005: 81)$ goes on to suggest that "if anything is underway, it is more a matter of evolutionary trends that evolutionary developments". The reality is probably one of both. Many of the trends that emerge within the manufacturing economy may well be in line with the continuous improvement paradigm that has its genesis within a Total Quality Management era, but equally well there are numerous cases where unexpected events have given birth to discontinuous change and trends that were not predicted or foreseen. The consequential outcome of such events and their disruptive impact on the operational activities of institutions suggests a response that is more in line with the unordered domains of the Cynefin framework than the ordered domains. Retrospectively cause-effect relationships can be determined in relation to the complex domain, but in many instances executives and managers are totally unable to recognize and pro-actively respond to the trends and events when they emerge. It is the difficulty associated with detecting and having to respond to emergent disruptive patterns in a dual economy that has given rise to executives resorting to the development of possible future scenarios that may well arise. Having thought through the consequence of such a trend emerging they would be far better positioned to deal therewith if it should materialise in practice. It is a typical response associated with a more ordered and deterministic context, with a strong rational underpinning logic. In the event of a scenario not even vaguely considered emerging, however, the executives and managers would be caught off-guard and the more likely situation would be one of chaos and having to resort to crises management. The two domains of complexity and chaos that define un-order in the Cynefin framework therefore assume increasing relevance in having to deal with the unpredictability associated with the global and South African dual economy.

In researching environmental complexity, it is argued by Stacey (1995:479) that organisations are assumed to be systems that in turn form part of larger environmental systems and as such evolve through a process of creative destruction and spontaneous self-organisation. South African business institutions are therefore deemed to form part of a larger global dual economic system. They consequently evolve unpredictably from interaction taking place between individuals within the organisational system in 
conditions of non-equilibrium and disorder that characterises the global and local economic system (Stacey, 1995:476). It is this self-organising and emergent property of the system, which cannot be predicted, that inherently characterise the domain of complexity and within which unintended patterns form and emerge. It is also a domain in which management practices appropriate within an ordered context loose their relevance, which consequently necessitates a change in management thinking and practice.

Day and Schoemaker (2004:137) warn against getting caught in restricted information cocoons and accentuate the need for institutions to create processes for serendipity. According to the researchers organisations in particular need to improve interpretation of information relating to emergent patterns by developing appropriate channels and networks for the sharing of information and the interpretation thereof. This tends to confirm the relevance of the IBM GIO initiative previously referred to as a means of detecting weak signals. Day and Schoemaker (2004:138) suggest that regrettably "organisational sensemaking is usually driven towards one single meaning" as a result of peoples' distain for ambiguity, while the worldview of complexity is one of diverse emerging patterns and alternative interpretations thereof. Kurtz and Snowden (2002) suggest that "understanding this space requires us to gain multiple perspectives on the nature of the system". In discussion with South African executives they tended to confirm a need for obtaining alternative views in dealing with what was termed to be the "fog of contextual reality". A number of them confirmed that in many cases their institutions made use of alternative scenarios, each presenting a different worldview of what may constitute future reality. By researching these alternatives it was suggested the institution was better positioned to deal with the contextual uncertainty of the global services economy.

Resilience in contexts of uncertainty and the emergence of unexpected and unanticipated events can best be realised by fostering a culture of accepting that failure and error are not abnormal occurrences. They are deemed to be part of real world-life experiences, that are best dealt with by anticipating and creating a sensitivity for detecting the first signs of the unexpected and acting thereon to avoid rationalisation activities. Weick and Sutcliffe (2001:66) suggest that resilience has its origins in a climate where "people are wary of success, suspicious of quite periods, concerned about stability, routinization, and a lack of challenge and variety that can predispose their organization to relax vigilance and sink into complacency that can lead to carelessness and error". At the very core of what may be termed a culture of resilience is a predisposition of anticipation and a need for expecting the unexpected to materialise.

\section{IMPLICATIONS}

The current so called "economic melt down" that has sent global markets into a tailspin serves as a case in point, as to the need for institutional resiliency. The preceding discussion assumes relevance in this regard, as it places an accent on the complexity of managing organisations in a world of unprecedented and unexpected change. The Cynefin framework could be used by South African managers, as a sense making tool, in order to determine the most pertinent response in relation to the contextual conditions encountered in practice. It is also hoped that the article will stimulate further discussion as to the importance of services science as an emerging field of contemporary management, one that will increasingly have a significant impact on business institutions globally.

Traditional management thinking is based on the concept of rationality and order, and the assumption of an underlying relationship between cause and effect (Davenport, Leibold \& Voelpel, 2006:68; Weeks \& Lessing, 1993:22 and Weeks, 2007:296), yet increasingly in the global services economy the reality confronting management appears to be quite different. This will imply that South African managers will need to turn to far more inclusive models of sense and decision making, models that extend beyond the boundaries of South African organisations themselves. The IBM global innovation outlook, discussed in this paper, serves as a good example of such an innovation engendering strategic process. In a highly networked and interconnected global services economy, South African intuitions need to become not mere spectators and victims, but active role players in shaping their future, failure to do will result in others shaping it for them by default. 


\section{CONCLUSION}

From the discussion it may be concluded that the Cynefin framework serves as a means of sensemaking, in relation to the nature of and most appropriate means of responding to the divergent contextual realities associated with a South African dual economy. The paradox of short term operational activities stand in contrast to longer term contextual uncertainty and the need for strategic direction, in what may be termed the contextual perfect storm, which is deemed to be representative of the global economy and in many respects the South African dual economy. It is suggested that complexity theory could be used as a means to more effectively understand and deal with the unpredictability associated with emergent global economic trends. This will undoubtedly necessitate a different management world-view from that associated with a more traditionally ordered manufacturing era. A contemporary era where the global economy is increasingly reflecting a significant trend towards services as a science in own right, needs to be seen in the context of a requisite for an integration of manufacturing and services at both an operational and strategic level, as it is argued that in many cases this remains a more true reflection of most developing nations' dualist economy, South Africa being a case in point.

\section{REFERENCES}

Akosile A. 2008. Africa: World Bank Seeks Faster Integration of Services Markets [Online] Available from: http://allafrica.com/stories/200802060519.html [Downloaded: 07/02/2008].

Axelrod R \& Cohen MD. 1999. Harnessing complexity: Organizational implications of a scientific frontier. London: Free Press.

Brown T. 2008. Design thinking. Harvard Business Review, 86(6):86-92.

Dalkir K. 2005. Knowledge management in theory and practice. Amsterdam: Elsevier.

Davenport TH, Leibold M \& Voelpel S. 2006. Strategic management in the innovation economy. Germany: Wiley.

Day GS \& Shoemaker PJH. 2004. Driving through the Fog: Managing at the edge. Long Range Planning, 37(2):127-142

Eisenberg EM. 2006. Karl Weick and the aesthetics of contingency. Organization Studies, 27(11):16931707.

Fitzsimmons JA \& Fitzsimmons MJ. 2008. Services management: Operations, strategy, information technology. London: McGraw-Hill.

IBM. 2006. Global Innovation Outlook 2.0. Armonk: IBM Corporation.

Kurtz CF \& Snowden DJ. 2003. The new dynamics of strategy: sense-making in a complex and complicated world. IBM Systems Journal, 42(3):462-483.

Lohr S. 2006. Academia dissects the services sector: but is it a science? The New York Times, 18 April [Online] Available from:

http://www.nytimes.com/2006/04/18/business/18services.html?ex=1169874000\&en=dee4341084b85982 \&ei $=5070$

Lovelock C \& Wirtz J. 2007. Macro Trends in the Global Economy: The Role of B2B Services. Presentation at Frontiers in Services Conference, San Francisco, 4-7 Oct 2007.

Mertzberg H. 1994. The rise and fall of strategic planning: Reconceiving roles for planning, plans, planners. New York: Maxwell. 
Metters R, King-Metters K, Pullman M \& Watson S. 2006. Successful service operations management. Toronto: Thomson.

Miles I. 2005. Services and the knowledge-based economy. (In Tidd J \& Hull FM eds. Service Innovation: Organizational responses to technological opportunities and market imperatives. London: Imperial College Press: 81-133).

OECD. 2005. The service economy. Science Technology Industry: Business and industry policy form series: 2005/3 working paper. OECD Publications, 2, rue Andr'e-Pascal, 75775 Paris CEDEX 16 [Online] Available from: http://www.oecd.org/dataoecd/10/33/2090561.pdf

OECD. 2007. South Africa: Africa economic outlook OECD [Online] Available from: http://www.oecd.org/dataoecd/26/61/38563040.pdf [Downloaded: 05/12/2007].

Peacock B. 2008. Technology is ahead of business maturity. Sunday Times Business supplement, May 25.

Peters T. 2003. Re-imagine! London: Dorling Kindersley.

Richardson KA. 2008. Managing complex organizations: complexity thinking and the science and art of management. E:CO, 10(2):13-26.

Snowden DJ \& Boone ME. 2007. A leader's framework for decision making. Harvard Business Review, 85(11):69-75.

Stacey RD. 1992. Managing chaos: dynamic business strategies in an unpredictable world. London: Kogan Page.

Stacey RD. 1995. The science of complexity: an alternative perspective for strategic change Strategic Management Journal, 16(6):477-495.

Stacey RD. 2000. Strategic management and organisational dynamics: the challenge of complexity. London: Prentice Hall.

Tidd J \& Hull FM. 2005 Managing service innovation: variations of best practice. (In Tidd J \& Hull FM eds. Service Innovation: Organizational responses to technological opportunities and market imperatives. London: Imperial College Press: 3-34).

Weeks RV. 2007. Context: The strategic management Rosetta Stone. Acta Commercii, 7:294-306.

Weeks RV. 2008. The services economy: A South African perspective. Management today, 24(2):40-45.

Weeks RV \& Lessing N. 1993. Strategic management: A turbulent environmental perspective. Johannesburg: NGK.

Weick KE \& Sutcliffe KM. 2001. Managing the unexpected: Assuring high performance in an age of complexity. 